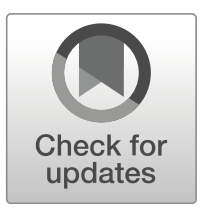

\title{
A Worker-Driven Common Information Space: Interventions into a Digital Future
}

\author{
Naja Holten Møller ${ }^{1} *$ (D), Maren Gausdal Eriksen ${ }^{1} \&$ Claus Bossen ${ }^{2}$ (10) \\ *1 University of Copenhagen, Copenhagen, Denmark; ${ }^{2}$ Aarhus University, Aarhus, Denmark
}

\begin{abstract}
This paper empirically investigates a Common Information Space (CIS) established by medical secretaries so they could support each other during their workplace's transition to a new comprehensive electronic health record, called the Healthcare Platform (HP). With the new system, the secretaries were expected to become partially obsolete, as doctors were to take on a significant load of the clerical work, such as documenting and coding. To handle their changing work situation, the medical secretaries set up an online support group in parallel to, but independent from, the official implementation support organization. The paper's contribution is a characterization of the support group as a common information space (CIS), and analysis of the specific qualities of a worker-driven CIS as a forum for 1) articulation work required for re-grounding changing tasks and responsibilities, 2) archiving discussions (posts) and guidelines to further their collective interpretation, and 3) creating a space independent of management for employees to work out their new role in an organization in a situation of transition and change.
\end{abstract}

Key Words: Workers' self-organizing, Common information space, Clerical work, Non-clinicians, Epic, Common ground, Electronic health record, Future of work, Datafication, Digital ethnography, Medical secretaries

\section{Introduction}

This paper explores how a group of professionals (medical secretaries) set up a Common Information Space (CIS) in response to their organization's transition to a comprehensive electronic health record, called the Healthcare Platform (HP) and their re-grounding of their changing tasks and responsibilities. The HP integrated several previous IT healthcare systems into one suite and allowed for data-driven practices. It also entailed new divisions of work across two of Denmark's five health regions, affecting in particular the group of hospital clerks comprised of medical secretaries. We focus on how medical secretaries used a closed Facebook group (from here on referred to as the Support Group) to respond to the dramatic change in their work situation; we conceptualize this Support Group as a worker-driven CIS. The medical secretaries negotiated possible new roles for themselves through long-term and sustained discussion:

The better experts we are [in terms of the new HP], the less can we be ignored and the better can we opt in on new, great, and exciting tasks. To sit with our hands idle and signal to them [doctors and nurses] that they have to learn it themselves, is 
only to our disadvantage. We have to be innovative and become the experts again. For god's sake, we cannot become inactive or passive. We are the red thread in a white world [of doctors] with or without HP.

\section{(Support Group 2017)}

The above quote demonstrates the nature of these discussions in the Support Group. CIS is a main concern for $\mathrm{CSCW}$ research focused on understanding how computational technology is socially embedded and may support the construction of shared meaning as people collaborate to accomplish their work (Schmidt and Bannon 1992; Bannon and Bødker 1997; Bossen 2002). We see the Support Group as a CIS for several reasons: First, the Support Group acted as a shared space for medical secretaries to "maintain a central archive of organizational information" and achieve "joint interpretation of these objects" (Schmidt and Bannon 1992, p.16). Second, the Support Group was also a space for medical secretaries to carry out articulation work necessary for sustaining the cooperative work arrangements at the hospitals (ibid, p16-20), an essential part of how the medical secretaries understand their occupation's contribution to the organization. Third, as stressed in Schmidt and Bannon's classic paper (1992) and as several subsequent papers have argued (Bertelsen and Bødker 2001; Bossen 2002; Zhang et al. 2017), CIS can take on different forms: for example, it can be co-located, 'massively distributed,' or online.

As a CIS, the online Support Group created a shared archive of guidelines, discussed how to interpret functionalities in the HP, and coordinated tasks and responsibilities across departments and hospitals. The latter concerned how to enter information and use the HP to ensure consistency of the medical secretaries' work across sites, as well as how to consistently cooperate with other professions. With the implementation of the new HP, healthcare staff, including medical secretaries, had to re-establish common understandings of system functionalities and practical divisions for work (e.g. procedures for how to book, order and code services). They had to overall re-establish how to maintain the digital information infrastructure, which includes but is not limited to the HP.

In this sense, the medical secretaries conducted articulation work, both involving doctors and nurses, and between themselves, in order to re-establish a systematic division of tasks for the overall cooperative ensemble (Schmidt and Bannon 1992). The secretaries had to re-coordinate and re-negotiate many of their tasks across 14 hospitals in the two health regions. These efforts of 'articulation work' (Schmidt and Bannon 1992), or 'grounding' to achieve common ground were crucial to the transition to HP. Common ground refers to the knowledge that the participants have in common, and they are aware that they have it in common (Olson and Olson 2000, p157). Grounding on the other hand refers to processes in which actors communicate and interact, aiming 'to establish that what has been said has been understood' (Clark and Brennan 1991, p128). 
A Worker-Driven Common Information Space: Interventions...

As we will show, the transition to the new comprehensive HP significantly changed the tasks and role of medical secretaries. A significant part of the documentation of the clinical work - previously carried out by medical secretaries - was re-delegated to doctors. However, the daily maintenance of the digital information infrastructure, including ensuring completeness of and validating documentation and coding, remained an important part of the medical secretaries' work.

This process in which medical secretaries are under pressure in the context of digitalization and changing workplaces (Møller et al. 2017b) in some respects mirrors experiences from 25 years ago in Denmark. At that time, computational system supported management overview, but not so the work of frontline staff of secretaries and labour inspectors. In that case management, staff and researchers began raising collective resources within the organization (Bødker 1993, 1994). In our case, management decided upon a new division of work, left secretaries to work out solutions themselves, and permitted no research on the implementation process; Only few studies relating to the HP, but neither upon medical secretaries nor the Support Group or CIS, have been carried out (e.g. Mørck et al. 2018; Hertzum and Ellingsen 2019).

The CIS Support Group that the medical secretaries created fills a gap left by the official HP organization of the two health regions. The official bodies did not acknowledge the role of medical secretaries as central to working out new cooperative arrangements between themselves and with other professions following the rollout of HP. Our case brings to the fore the 'repair work' required when large infrastructures change (Steinhardt 2016), and we consider in this paper how recent CSCW research on support for workers' self-organizing and online support groups (i.e. Da Cunha and Orlikowsky 2008; Irani and Silberman 2013; Ménendez-Blanco et al. 2017; Harmon and Silberman 2018; Martin et al. 2016) connects with new agendas on the transformation of classic types of work (Pine et al. 2016; Dombrowski et al. 2017; Kristiansen et al. 2018; Møller et al. 2020).

The overall question we ask in this paper is: What are the qualities of a workerdriven CIS and how does it support re-grounding of medical secretaries' practices and carving out a new role in connection with technological change and transition?

We explore this question through the case of medical secretaries, analyzing content posted in the CIS (Support Group) between March 2017-October 2019. Inspired by digital ethnography (i.e. Hine 2000; Hsu 2012; Pink 2015), this approach allows us to simultaneously engage with the unique data set the medical secretaries themselves created (posts, documents, and screen dumps) offsite - and on the other hand supplementary data from onsite interviews with medical secretaries working in HP in 2 hospitals (October 2019). Thus, a key characteristic of digital ethnography is that it is multi-sited and combines the analysis of different types of data (ibid). 
In total, we analyzed 857 unique content posts. Approximately $9 \%$ of the 2000 medical secretary Support Group members across the two health regions posted content. On a daily basis, medical secretaries shared 2-3 unique posts on the Facebook group, seeking answers on concrete issues. Our case illustrates the important qualities of a CIS during periods of transition and change, as technology and new divisions of work demanded by management transform cooperative work. CIS have been studied in hospital contexts before (Bossen 2002; Zhang et al. 2017), but not under this kind of dramatic transformation of the overall division of work. The creation of the Support Group makes visible the ripple effects of new technology and how a CIS enables new types of worker-driven engagement.

The paper's contribution is a characterization of the Support Group as a common information space (CIS), and an analysis of the specific qualities of a worker-driven CIS as a forum for 1) articulation work required for re-grounding changing tasks and responsibilities, 2) archiving discussions (posts) and guidelines to further their collective interpretation, and 3) creating a space independent of management for professionals to work out their new role in an organization in situations of transition and change.

The remainder of this paper is structured as follows: Section 2 reviews prior $\mathrm{CSCW}$ research on data work, CIS, and digital labour platforms; section 3 presents the case and method; section 4 analyzes the CIS set up independently of the health regions' official HP organization; section 5 discusses the case in the broader context of online support groups and digital labour platforms, and finally section 6 concludes and provides suggestions for future work.

\section{Related Work}

The role of professional work and how computational technology can best support it is a long-term interest for CSCW research. New emergent technologies change or even replace the routines and roles within an organization (Schmidt and Bannon 1992; Schmidt and Bannon 2013). Within healthcare over the last decades, digitization has profoundly changed work practices in connection with the implementation of EHR's to enhance coordination, documentation, sharing of information and becoming data-driven (Fitzpatrick and Ellingsen 2012).

Digitization within healthcare, including the implementation of EHRs such as the HP, can speed up the exchange of updated information on diagnostics and treatment and enable immediate coordination across time and space, and hence lessen the effort of cooperation, coordination, and communications. However, since the healthcare domain is characterized by a high degree of complexity in terms of coordinating tasks across multiple sites and medical specialties (Strauss et al. 1985), organizations' digitization is a challenging and not always successful endeavour (Bossen 2011; Greenhalgh et al. 2009). 
A Worker-Driven Common Information Space: Interventions...

Accompanying digitization is the ability to exchange and accumulate data, such that healthcare organizations can become more accountable and data-driven or -informed (Andersen et al. 2018). Increased and immediate access to more up-todate data is transforming the healthcare domain, providing new opportunities both in terms of how complex, cooperative work tasks are accomplished - as well as demanding more work entering data and ensuring that it is complete and valid (Pine et al. 2016).

With ongoing digitization and intensification of data resourcing in healthcare (Hoeyer 2016; Hogle 2016), it is critical to understand for both practitioners and management how the work of digital transformation and generating data is accomplished in times of transition and change. We turn our attention to prior research on the transformation of work with a specific focus on how medical secretaries have played a central role in healthcare's digitization.

\subsection{Digitization, Change and the Role of Clerical Work}

Management's interest in data and digitization of healthcare reintroduces some of the same questions that drove research in CSCW and related fields in the 1980s, when desktop computers were introduced in offices and 'office automation' was a significant issue to workers (Møller 2018). At that time, secretarial work was also the object of study and concerns were raised by researchers and unions about its demise (e.g. Suchman 1983; Blomberg et al. 1997; Markussen 1996). Computer-supported automation and systems integration made data easier to share and reduced the need for clerical work, it was assumed. Secretaries were expected to become obsolete (ibid).

As it turned out, the secretarial occupation has not disappeared (England and Boyer 2009; Truss et al. 2012), just as the digitized office has not become paperless (Sellen and Harper 2002; Heinrich et al. 2018). In healthcare, the opportunities for data-driven development of hospital operations introduced by EHRs and other digital systems have not made medical secretaries redundant; rather, they have demanded that medical secretaries take on new tasks. The new types of data available have created a demand for new competences and data work, for example, a broad and deep contextual understanding of how data are produced. Sometimes data are repurposed for uses unanticipated at the time of creation. For example, health data can be used for decision-making about peoples' work ability in social welfare (Møller and Jensen 2016; Boulus-Rødje 2018; Møller et al. 2019), evoking data's multiple social lives (Fiore-Gartland and Neff 2015). Furthermore, secretaries (still) play a key role in ensuring the complex alignment of technology and personnel within a healthcare context (Møller and Bjørn 2011; Møller and Vikkelsø 2012; Bossen et al. 2012; Møller 2018; Bossen et al. 2019a, b). With the increased importance of data work, medical secretaries will also have a key role in maintaining, ensuring completeness, and validating health data. 
Medical secretaries play a central role in hospitals as 'articulation workers' (Abraham and Reddy 2013), since they integrate and maintain healthcare infrastructures and medical records on a daily basis. This role became especially pronounced in the process of implementing the HP. Transitioning from an old to a new system is not a dichotomy where the new system completely replaces the old (Steinhardt 2016). Retiring technology - as well as software - takes careful consideration to think through legacy, and the complex relationship between new and old (Cohn 2016; Steinhardt 2016); thus, we fail if we do not recognize what makes a graceful retirement of digital systems and scaffolding of new ones (ibid). The deep relationships that healthcare practitioners build with technology and the path through old software and technology are not simple to trace in a process where one system is replaced with another. Practitioners across different contexts build relationships with digital systems through years of work. Medical secretaries do so in their daily work of artfully stitching together the variety of systems, artefacts, and data streams that are characteristic of healthcare, or in some cases as they discard them with care (following Steinhardt 2016).

The present case illustrates why it is critical particularly for an undervalued occupation of workers to negotiate and articulate their role and re-ground practice when new technologies are introduced. In many ways, the graceful retirement of old technologies and transition to new data-driven ones requires work characteristic of what medical secretaries do. However, despite their key role in organizational and technological change projects in healthcare as 'super users,' secretaries continue to be invisible to management, and new data-driven systems such as the HP are designed to displace them based on the premise their work will become redundant.

\subsection{CIS as a Forum for Transition and Change}

The secretaries' formation of the Support Group independent of the official organization and management is an empirical example of how a group of professionals work to maintain a strong position for themselves in a changing workplace. As a group sharing expertise and common fields of work, medical secretaries represent a community of practice (Lave and Wenger 1991). The Support Group may also be regarded as an instance of knowledge and expertise sharing through the creation of an organizational memory built on a shared database (Ackerman 1994; Ackerman et al. 2013). However, since this group went online aiming to efficiently share their knowledge and expertise, and went beyond the notion of organizational memory of how things used to work, we frame our analysis through the concept of CIS to stress the digital working out of common understandings and practices in the Support Group.

CIS in its classic formulation is characterised by "maintaining a central archive of organizational information" (Schmidt and Bannon 1992, p16). Such an archive requires an active construction of meaning by the actors involved, where the meanings of the shared objects are debated and resolved, at least locally and 
A Worker-Driven Common Information Space: Interventions...

temporarily (ibid, p27), what we refer to as grounding in this paper. In exploring the shortcomings of repository models, Ackerman (1994) argued that times shift and sharing information is dependent on making that information relevant (meaningful) in the particular situation. Information (e.g. guidelines) will often become outdated before it is even brought to use. Instead, the goal for building guidelines should be support of interaction (Ackerman 1994).

Further elaborating the concept of CIS, Bannon and Bødker (1997) and Bannon (2000) point to the added work actors continuously invest to ensure they understand each other's information context. A CIS has dialectical characteristics, they argue - they are both open and closed at once. A CIS needs to be open, malleable and interpretable, while also providing closure, where information is 'packaged" in order to enable sharing across context and communities of practice (Bannon and Bødker 1997). This characteristic of being both open and closed acquires a new meaning in the context of change and transition, because it allows for the renegotiation of meanings, procedures, and divisions of work by the secretaries.

In the present case, a negotiation of medical secretaries' role and their cooperation with other professions was necessary, as the HP changed the overall organization of work. A CIS can take on different forms: it can have a coordinative centre or be distributed, with actors gathering and making sense of information as they move between various sub-zones (Bertelsen and Bødker 2001; Bossen 2002). In this case, with members of the Support Group distributed across 14 hospitals, the closed Facebook group remained the central space for interaction. As a relatively simple technology, the Support Group can be seen as both open and closed. It provides a central archive in the form of shared repositories of guidelines, and a space for posting questions and resources and working out how to proceed with work.

\subsection{CIS and Enterprise Social Media (ESM)}

More and more organizations are using so-called enterprise social media (ESM) to support work, with Workplace by Facebook and Slack as widely adopted examples (Leonardi et al. 2013). Here employee voice and workplace democracy can be fostered through, for example, constructive moderation and positively impact employee wellbeing (Abdulgalimov et al. 2020). Workplace by Facebook (WbF) allows employees to form groups to discuss particular projects or topics and share documents. At the same time, it leaves behind ideas of information as being situated and socially constructed when information streams are curated: According to the company, the WbF news feed uses Artificial Intelligence (AI) to sort information and make sure that the individual employee will only see posts from the 'right' people and projects (Workplace by Facebook 2019). The premium version allows for monitoring tools and other types of data analytics for management, such as compliance providers (Workplace by Facebook accessed on February 9, 2019). Such platforms can work as a 'leaky pipe,' in which broad knowledge helps build bridges; as an 'echo chamber' to build common ground through interaction and sense of 
belonging; or as a 'social lubricant' that helps practitioners initiate new connections and maintain established ones (ibid p. 9). Despite ESM holding promises for (re)defining the workplace, these are not always experienced by employees as social, open, or participatory, but rather as a managerial tool, and the question arises "... whose purpose is served by the technology?" (Denyer et al. 2011, p393).

As found by (Da Cunha and Orlikowski 2008) and (Ménendez-Blanco et al. 2017), online forums or support groups can be used to exchange information, coordinate work, and for emotional support in contexts of organizational change. They may have the effect of providing space to express anger and loss, while at the same time accommodating the changes that employees find problematic (ibid). Support groups during organizational change raise a number of questions: How might they be useful to occupations and professions that are considered redundant to an organization? What role will algorithms and AI play when sorting posts based on criteria of relevance - and how are these criteria decided on? Such questions are critical for how a CIS can be a platform for transition and change 'by design.' The Support Group is similar to ESM in the sense that it is a forum for facilitating organizational change and a space to express emotional stress at the same time, but differs in that it was set up independent of the organization.

A related, but somewhat different perspective focuses on the use of digital labour platforms to support workers (Irani and Silberman 2013; Silberman and Irani 2016; Harmon and Silberman 2018), and addresses how to think through new uses of platform technology from an employees' perspective. These studies show how emergent technologies often hide the people and data work (still) required to perform a service, creating invisible labour. Content moderators, for example, sanitize the internet to provide a seamless Facebook feed or advertisement (Irani 2015). Similarly, medical secretaries work in the shadows to facilitate the transition and change following the rollout of the HP

Enabling workers' power is critical as data-driven technologies march on (Harmon and Silberman 2018). In healthcare, self-employed transcriptionists are paid per line they transcribe, while designers work to displace them through the understanding that once entered into a system, data can be used and reused without any further contextualization (Vinik 2018). Students are hired to enter data and keep up with documentation and data entry (Bossen et al. 2017). Management upholds the idea of a future where clerical work is redundant in hospitals, while in fact tasks simply shift hands (Møller 2018). Employees are also beginning to understand how they can use technology for the mundane negotiation of their working conditions with their organization when they track their working hours or document the accomplishment of tasks (Dombrowski et al. 2017; Kristiansen et al. 2018).

The Support Group in this case bears some similarity to platforms such as Turkopticon (Irani and Silberman 2013) and Dynamo (Salehi et al. 2015), in the sense that they both take a practical approach to supporting undervalued workers. Turkopticon included a 'reputation system,' in which workers can avoid employers with bad requests and reputations, favor those with a good reputation, and exchange 
experiences on how to navigate this online labour market (ibid). By evaluating and announcing their work relation to companies, the site becomes a platform of information-sharing and for Turkers' negotiation of their work conditions. Similarly, the Support Group set up by the medical secretaries independently of their employer can be understood as a platform where they maintain their transparency and visibility towards each other and at the same time negotiate a future role for themselves, as we will show below.

We shape this paper around the worker-driven supportive and self-organizing qualities of the Support Group, set up as a CIS by the group of medical secretaries. Taking this perspective, we want to bring to the fore the extra work required with large infrastructural or technological change and consider lessons from prior CSCW research on support for undervalued workers. We point to the parallel way in which digital platforms for support of new and old occupations can be leveraged independent of management to re-ground tasks and negotiate a new role for themselves in situations of transition and change.

\section{Method and Case}

The Support Group for medical secretaries emerged in connection with the implementation of the HP, the new comprehensive EHR. HP replaces a number of non-integrated systems and is envisioned to collect, store, and display integrated patient information across diverse healthcare providers (Ajami and Bagheri-Tadi 2013). The aim is to provide healthcare professionals as well as patients with a broad overview of patient data and enhance patient safety (Region Hovedstaden 2019). The procurement of the HP is Denmark's largest and most complex health-IT project to date. Implementation began in 2016 at one large and one small hospital, and since then the HP has been adopted at the remaining 12 hospitals in the two health regions.

As an off-the-shelf EHR, HP, was developed by Epic in the USA, and sold and adapted to a range of countries, including the United Kingdom, Netherlands, and now also Denmark and Norway (Hertzum and Ellingsen 2019). Significant challenges have been reported across these countries in the wake of implementing the HP (Rigsrevisionen 2018). In Denmark, productivity in hospitals fell by more than 5\% per year after the implementation of HP (Rigsrevisionen 2018).

The Danish Public Accounts Office published a report criticizing the implementation of the HP against the backdrop of the problems observed, particularly concerning documentation work and whether it complied with administrative rules (Rigsrevisionen 2018). This probably relates to the fact that medical secretaries no longer have the same rights and access within the HP as in the previous systems. Instead, another professional group (doctors) is now responsible for documenting clinical work. This change in the division of work between occupational and professional groups is reflected in how documentation of clinical work (e.g. patient notes) and coding for reimbursement are now strongly tied together: While doctors 
can view, enter, and edit information, medical secretaries may view, but have limited ability to edit.

\subsection{The Official IT Support during the Implementation of the HP}

The official IT support in connection with the implementation of the HP basically consisted of the following items: the health regions' intranet as a carrier of information (guidelines, tips sheets etc.); a learning portal for doctors, nurses, and secretaries; the hospitals' IT helpdesk; and, finally, clinical 'super users' in each hospital department (e.g. so-called 'builders' that can customize certain parts of HP, typically a doctor). The official support can be regarded as another CIS, in parallel to the medical secretaries' Support Group, but it is directed at all professionals within the 14 hospitals.

Medical secretaries experienced several challenges with the official support. Initially, they were not invited to attend the training of hospital staff provided as part of the implementation process signalling, one may argue, that their work was not considered important back then in the context of the HP. The formal guidelines for how to use the HP are not easily accessible on the hospitals' intranet, and medical secretaries often find them misleading. The guidelines are directed to everyone, and thus too general to cover the specific needs of medical secretaries (Group interview, 0103 2018). Also, the intranet mainly provided information about the implementation of HP in general terms, but not at the level of possibilities for adaptations to local practices (Medical secretary, Group interview, 0103 2018). The lack of updates impacted not only their own work, but also their previous role as support for other professionals regarding IT

This role as problem-solvers has developed over the years in a process where medical secretaries have seized and were delegated new activities and tasks as local coordinators, local IT-support etc. Unlike other professions, they are easily located and accessible, since they work from the same office desk most of their day. They have become an established resource for finding solutions for coordinative challenges around treatment and care for patients, including the use of the hospital systems (Bertelsen and Nøhr 2005; Bossen et al. 2012, 2014; Møller and Vikkelsø 2012; Møller 2018). It has been a natural part of their work to continuously adapt and find new solutions to issues related to the digital flow of the hospital work. In this sense, medical secretaries are important for the ongoing articulation- and 'repair work' necessary to keep work arrangements stable and on track, especially across many different systems (following Steinhardt 2016).

\subsection{The Support Group: Independent of Management}

Frustrated by the lack of support from the health regions' official implementation organization, a medical secretary started the Support Group as a private interest group in March 2017, using mainstream social media (Facebook) as a platform. She 
A Worker-Driven Common Information Space: Interventions...

aimed to support her colleagues' work at 14 different hospitals distributed across the two Danish health regions implementing the HP by providing a space where medical secretaries could gather and share their experiences with the new EHR (e-mail correspondence with the administrator 0703 2018).

In the beginning, the administrator simply invited all the medical secretaries that she knew and asked them to extend the invitation to their colleagues. When the day arrived to go live with the group, 2000 medical secretaries, or approximately $\sim 57 \%$ of the total number of medical secretaries across the two health regions and yarious medical specialties, had become members (ibid). In all, there were approximately 3500 medical secretaries employed in the two regions at the time. A few of the group members were not secretaries, but rather reporters, politicians, researchers, and people working in IT-support. Members can invite others to join the Support Group, but new members must be approved by the administrator. The Support Group's purpose is stated as: "A group for medical secretaries that experience issues with $[\mathrm{HP}]$ in their daily work. Support is often faster between secretaries" (Support Group for Medical Secretaries, accessed on January 31, 2019). However, as we will show, the Support Group also acquired a much broader role as a space within which the secretaries could negotiate a new role for themselves.

The two main functionalities of the Support Group are a news feed, and an archive of guidelines. The news feed is chronologically ordered and provides the same functionalities as a private Facebook account: Members of the Support Group can post, comment, and like other members' posts. Thus, the Support Group is technically simple: based on posts and a 'flat' archive of guidelines regarding the HP. The typical posts concern various questions related to the new HP that arise as part of their daily work. Posts often include screen dumps to point to and visualize the concrete issues that the secretaries encounter, and discussions or clarifications about how the HP works. The archive of guidelines extends the functionality of the Support Group beyond an interest group. Currently, the Support Group archive counts 36 guidelines shared by the medical secretaries. They are documents that support the required articulation necessary to re-establish a systematic division of tasks, as mentioned earlier.

\subsection{Data Collection and Data Analysis}

We were granted access to the Support Group with the consent of the administrator, and Support Group members were informed about the research project and given the choice to opt out. Posts are curated by the administrator of the Support Group, ensuring for example that no sensitive information (e.g. on patients) is found in posts or photos uploaded by members. For reasons of privacy, we have anonymized all data, and people cited have been labelled [Name 1], [Name 2], etc. starting anew with each citation (i.e. [Name 1] in one citation is different from [Name 1] in another). Data was manually downloaded in accordance with rules applying to private groups. Finally, all researchers comply to their universities' code of conduct. 
The basis for the study was a multi-sited, digital ethnography (i.e. Hine 2000; Hsu 2012; Pink 2015) applied to understand the role of the Support Group. In addition to studying interaction digitally, the same tool set is applied to the digital field site as would be applied to an analogue field site, such as strategies to understand a certain practice. For example, we were following an analytical strategy where we mapped out the use of a particular digital artefact (i.e. guidelines) and the sensemaking around new HP 'objects'.

On a daily basis, 2-3 unique posts were submitted, which accumulated to 857 content posts submitted between March 2017-October 2019- this is the set we analyzed. These were posted by approximately $9 \%$ of the 2000 medical secretary members of the Support Group, whereas $23 \%$ of the medical secretaries in the group commented on posts (member post and comments are both counted in each of these groups). On average, the number of comments was 5.7 per post. The Support Group helped medical secretaries face the challenges of working with the HP, though one limitation of the study is the understanding of 'posts' and 'commenting' as a proxy for 'interaction.'

When considering reports of ongoing research into Facebook groups in Denmark, this indicates the mean number of posts per year for 'private' groups to be around 160 , and the mean number comments to be around 400 per year (Kim et al. 2017). Within the first year of existence, $\sim 700$ posts were entered, thus indicating a rather high degree of interaction, even for a large group by Danish standards. The following year-and-a-half, only $\sim 150$ posts were entered, signalling, we think, that the Support Group was especially important in the first period of transition to HP. Research in the USA found a mean number of $0.6 \%$ contributors (vs. lurkers) in enterprise social media groups (Muller, 2012), and in general social media members are said to consist of $90 \%$ readers; $9 \%$ content editors, and $1 \%$ contributors (Sun et al. 2014). With $9 \%$ as contributors, the Support Group comes out at the high end of activity, which aligns with the fact that Support Group was formed at a time of rapid change, and our data is from this same period. The total number of comments across posts in the Support Group during the period of study is 4382 (March 2017-October 2019).

Since posts address issues with the new system, the HP, and often include screen dumps, it seems safe to assume that at least the majority of medical secretaries that post or comment are actively working with the new system in a hospital in one of the two health regions (i.e. they are not among the group of medical secretaries that were made redundant by the HP). The group is not set up for supporting the entire community of practice comprised of medical secretaries across Denmark's 5 health regions, since only 2 of the regions have procured HP.

\subsubsection{Identification of Themes that Are Task-Related}

As a first step, we wanted to identify themes in the data that are tasks-related and regrounded by the medical secretaries using the CIS. The second author collected all content (i.e. posts, conversations, documents and screen dumps) published in the 
A Worker-Driven Common Information Space: Interventions...

Support Group in the first year of its existence. We later extended the data collection to include posts until October 2019. In total, data counts 2,5 year of posts.

We ran a word frequency query, focusing on words that were 10 characters or more (to avoid conjunctions) as a baseline for our analysis of tasks that the secretaries re-grounded. We then compared the list with a word frequency query of minimum five-character words, aiming to make sure that we were not missing significant words, though in principle we may have missed short abbreviations in this process of generating the list presented in Fig. 1.

\subsubsection{Identification of Themes that Are Not Task-Related}

As a second step, the analysis focused on identifying themes in the data that could not be related to the re-grounding of tasks, but instead addressed questions such as the future role of the medical secretary occupation. Applying open coding and taking a grounded theory approach (Glaser and Strauss 1967), we were able to further explore the results of the word frequency query.

The software itself is not capable of segmenting the data into meaningful themes to 'clean' the data; thus, we used sticky notes to simultaneously make sense of the query and identify themes across posts - also as a basis for the discussion amongst ourselves. Once the results of the query were organized

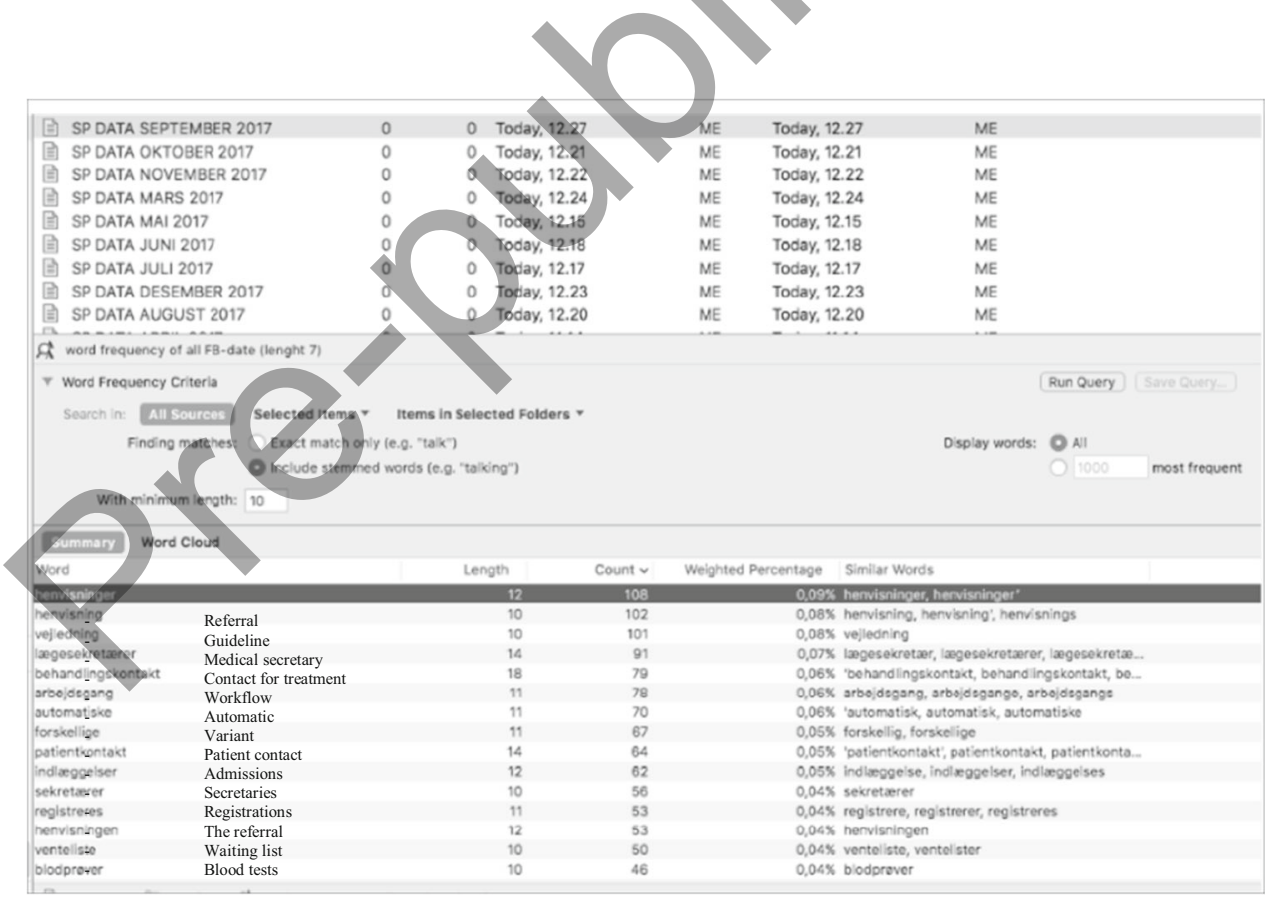

Fig. 1. NVivo 'word frequency query' of key words across each month (admissions, registration etc.). The list forms the baseline for the analysis of tasks that are re-grounded by the medical secretaries after the transition to the HP. The second column is our translation of the first column (bottom) from Danish into English 
into overall themes, we could make a query for each of these tasks by searching for relevant keywords in the dataset.

Examples of themes that emerged from this part of the data analysis and that we considered as non-task specific relate to discussion on whether the medical secretaries should actively engage in the guiding of doctors on how to use HP correct-or not, as we will see in the analysis later in this paper.

\subsubsection{Verifying the Themes in Interviews}

Third, to supplement our results from the NVivo analysis, we conducted qualitative interviews. In Hospital A, we conducted three group interviews between 2017 and 2019: One with the secretaries working a medical department 'day clinic' $(n=3)$, and another with secretaries working with a surgical 'bed ward' $(n=2)$. An additional group interview was conducted in 2019 within the same medical department 'day clinic' $(n=3)$. In Hospital B, we interviewed one secretary working in the medical department, and conducted three interviews with the same senior doctor with a special interest in HP between 2017 and 2018. Finally, we conducted an email interview with the administrator of the Support Group.

A closer look at selected content posts, and contesting our first rounds of data analysis with the interview data, confirmed in several examples that secretaries regarded the Support Group as part of a strategy for becoming experts (again) with respect to EHRs, in this case the new HP. This understanding shifted our focus towards the qualities of the CIS in relation to labour self-organizing for professionals when jobs and organizations are transformed by new technologies.

Through these interviews, we further explored the themes identified in the analysis of posts, including the issue of how the new HP became an opportunity for secretaries to negotiate their future role. The different types of data from the digital and analogue field site together informed the study to answer questions on how medical secretaries negotiate the use of HP (re-ground practice) - and their future role as part of this. In this sense, digital ethnography allows for a contextualization of finding across fields sites (following Hsu 2012 and others).

\section{Analysis: The Support Group CIS}

"I spend too much time on error correction of codes and on reminding doctors to check their 'In Basket' [mail box] during a work day", said one of the medical secretaries in the office. She complained that changes have occurred in the management of patient administration after the implementation of HP. Doctors and nurses have been given the task of entering diagnostic codes. This was previously a task of the medical secretaries. Now, because of this change, the majority of the doctors are not precise and consistent with the registration of codes".

(Medical secretary, group interview, 0103 2018) 
A Worker-Driven Common Information Space: Interventions...

The vignette illustrates how the secretaries detect errors and correct doctors' entries in the HP as a significant part of their day-to-day work. One objective for the HP was to ensure that clinical documentation was performed by the source of information itself, the doctors. However, doctors were often imprecise in their writing. This also pertained to administrative issues such as attributing diagnostic codes, which are crucial for reimbursement.

Hence, ironically a new task for medically secretaries was to curate doctors' records, check error lists, and make doctors correct errors. This enabled the vision that doctors would do the documentation to be upheld. This narrow work contrasts with medical secretaries' previous, more expanded role, and was one of the ways in which their work portfolio changed.

The changes in work were due to either embedded procedures within the HP, or to a new division of work between occupations, and in both cases necessitated medical secretaries to engage in processes of re-grounding their work to establish shared meanings and understandings of functionalities, tasks, and procedures, as well as articulation work, to established new cooperative arrangements between themselves and other professions.

\subsection{CIS as a Place for Re-Grounding, Articulation Work and a Central Archive}

Medical secretaries are trained in communication, information sharing, and IT systems, and rely on apprenticeship learning for part of their training. With the same basic healthcare education and experiences, as a group they share a significant amount of common ground, and a mutual understanding of the work that they accomplish in hospitals. Such common ground must continuously be renegotiated and re-grounded, especially with a new EHR such as the HP; they accomplished this by posting, liking, or even simply following the debate of the Support Group.

In the following subsection, we will further explore how re-grounding and articulation work was facilitated through the Support Group and focus on four key issues: 1) the central archive of documents, 2) new tasks around data quality, 3) maintaining digital trajectories, and 4) support of the creation of a new role for medical secretaries independent of management.

\subsubsection{Central Archive of Documents}

In the Support Group an actual archive, exemplifying the role of the CIS as a central archive, is available since particularly useful guidelines are shared in the 'files' as a 'flat' archive that posts can refer to. A search mechanism allows any member of the group to look up, for example, 'in basket,' 'referral,' or similar key words that make

\footnotetext{
${ }^{1}$ Medical secretaries also work in the private practices of medical practitioners, but in this paper we only deal with the ones employed at hospitals.
} 


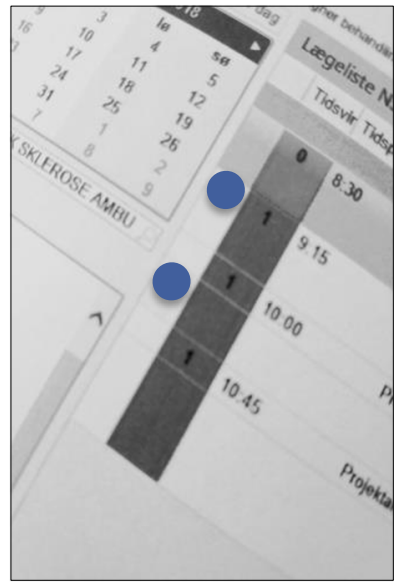

Fig. 2. Post illustrating the medical secretaries' use of the Support Group in this case for interpretation of what a blue dot means in the doctors' digital program

sense in their profession. The following extract from a post shows how the Support Group is used to make sense of features in HP:

At the time of data collection, there were 36 guidelines in the Support Group files. Because of the restrictions on Facebook private groups, the secretaries cannot structure and categorize their informal guidelines. Instead, they are listed according to the date when they were uploaded. These guidelines provided the basis for establishing similar procedures for their work and for consistently cooperating with other healthcare professions.

[Name 1]: The mysterious blue dots

In our clinic nobody knows where these blue dots come from? Who puts them there? The system? And why? Nobody here knows. Does any of you know?'

[Name 2]: Some of our doctors use them to get an over-view of the patients [in the clinic] on that particular day. I.e. red dot $=$ patient absent. I use them to mark the end of a patient visit, to save paper

[Name 3]: We use them in the day clinic to get an over-view of how far the patients are in their visit, when they first have to see a nurse and then a doctor before they are [marked as] finalized in the time schedule.

[Name 4]: The system automatically adds the blue dots every time you have placed an order (i.e. blood tests) (-) 
A Worker-Driven Common Information Space: Interventions...

As the HP entailed novel functionality and labels across professions, medical secretaries had to re-ground processes across hospitals, professions, and local practice to ensure their shared understanding, as illustrated in the example above (Fig. 2). Here the secretaries discuss the interpretation of shifting status in the doctors' calendars represented by a blue 'dot' and how to make use of this new functionality in HP.

In another example a medical secretary points the other Support Group members to a specific guideline in the 'flat' archive. This guideline is a further development of the health regions' formal guideline for closing a patient's case and transferring responsibility to another provider (e.g. a general practitioner). In the post, the medical secretary clarifies "what is new," and offers to upload a new version of the informal guideline, since the latest update of the HP requires an extra practical step in case of a patient "no show" (when a patient misses her og his appointment).

[Name 1]: Does anyone know how to close [discharge] a patient to the general practitioner?

[Name 2]: $\quad$ Can you be a bit more specific? Admitted patient or outpatient?

[Name 3]: If it is an outpatient, we have a guideline in here $(-)$ called Closing of patients

[Name 1]: It is an outpatient

[Name 3]: Then have a look at the guideline. I believe that the only new thing in there is that you have to close the referral [in addition to the patient case] if you never actually see the patient. I can upload a revised version of it [the guideline] by tomorrow.

[Name 1]: Thank you so much

[Name 3]: You are very welcome $(-)$

(Support Group, 2018)

The following list of tasks that required re-grounding in HP is based on the NVivo analysis of posts from the Support Group; yet, we assume that it only reflects the tasks that cause problems and merit the effort of posting. Tasks that stayed the same or where re-grounding was easily resolved are not included. While it does not reflect a complete picture of the tasks of medical secretaries working at these hospitals, it 
provides an idea of their task portfolio and how they experienced the changes and their new roles after the transition to the HP.

- Error correction (e.g. correct and/or curate doctors' entries into the HP)

- Ensure progress (e.g. ask doctors to document clinical notes in order to notify the patient on test results etc.)

- Workflow optimization (e.g. align doctors' calendars within the HP and fill gaps)

- Investigate and develop efficient use of new technology (e.g. optimal use of scheduling tools)

- Information transfers (e.g. ensure specific information is shared with the relevant nurses, doctors, and patients)

- Monitor the digital flow of tasks within the HP (e.g. remind doctors to check messages in their 'In Basket' mail box)

- Register data in the HP (e.g. registration work, including closing patient trajectories for reimbursement, etc.)

- Processing digital letters (e.g. sending digital letters to patients and general office maintenance)

- Order additional tests (e.g. ordering additional blood tests from labs or scans from the imaging section)

\subsubsection{New Tasks around Data Quality}

One major new set of tasks for the medical secretaries' concerns attending to and correcting data. One of the new functionalities that emerged with the HP and with the new division of labour is an automatically generated list of data entry errors. The secretaries are expected to systematically review and correct these errors. Secretaries are highly attentive to registering the time of a patient discharge in order to reduce the otherwise enormous amount of error reports that the HP will generate. They also supervise other practitioners' data work to ensure entries are made in the correct places in the HP (Medical secretary, group interview, 0103 2018). In the NVivo analysis, this was reflected in posts relating to medical secretaries' development of an efficient use of new technology for the organization as a whole. The medical secretaries had mixed feelings about their new work portfolio. On the one hand, the development of efficient use of the HP is frustrating to many medical secretaries, because it is difficult for them to support doctors and nurses in their struggles with the new data work (Medical secretary, group interview, 0103 2018). The HP provides different interfaces and access to different occupations and professions, which makes it hard for medical secretaries to fully understand an issue when a doctors or nurse asks for help. This in turn makes it challenging for them to take on these repair tasks, despite being willing to do so. On the other hand, with the implementation of the HP, doctors and nurses have a better sense of secretaries' work and role in the collaborative work around patients, including data work. Doctors and nurses now 
A Worker-Driven Common Information Space: Interventions...

understand how these tasks exist in their own right (ibid). It was only when the digital workflows broke down that other professionals began to understand how much work it took to continuously enter, monitor, and error correct digital patient records and trajectories.

The Support Group allowed the medical secretaries to efficiently cooperate at a large scale around issues such as error correction, which comprised a large part of their workday. For example, secretaries working across medical departments can gain valuable information about a specific workflow, such as how to correctly make entries in the National Patient Register (in Danish LPR, LandsPatientRegistret). This is a critical task in hospitals, since this data is used for: research; the national authorities' monitoring of diseases on a national level; as well as monitoring of activity, efficiency and quality across different hospitals and regions. Medical secretaries were also responsible for the entry of information to this kind of national register before the new comprehensive HP. With the $\mathrm{HP}$, they are now responsible for overseeing only the quality of coding that is (in principle) carried out by doctors and nurses. However, coding and missing entries became a massive problem with the HP, and overall the number of incorrect registrations to the National Patient Register alone was estimated at 100,000 in 2017 (Mølsted and Falsing 2017a, b).

Extracting a list of registration and coding errors from HP became an issue in itself, and is important for ensuring that the relevant information is transmitted to the National Patient Register, as the following example shows.

[Name 1]: How do you extract a list of the registration errors in the National Patient Register? Do you need certain rights?

[Name 2]: You will find the 'contacts' [of specific patient] with errors in the 'missing final registration' $[\log ]$ and 'open contacts with errors' [list] but there is no separate list as such.

[Name 3]: If you go through the list and correct the errors, it is not necessary [to extract a list]?

[Name 1]: Our clinicians have registered it as cancellations, so therefore they [the errors] have disappeared from the sorting mechanism, so now I know what to inform them about tomorrow.

(Support Group, 2018)

The above post provides an example of the medical secretaries' changing tasks, and their crucial role in ensuring correct registration of information across contexts and thus data quality. It also shows how medical secretaries define a new role for themselves through the collective negotiation of shared meaning in the Support Group. The last secretary in the example concludes that she will have to inform 
the clinicians the following day in order to make sure that they register the particularly type of information in the right way. It is clear from the post that she both feels responsible for as well as some form of authority to make sure that doctors' practices are changed within her hospital department.

More generally, the example illustrates how the secretaries utilize the Support Group to share knowledge and expertise on how to ensure the data quality on a dayto-day basis, while simultaneously negotiating a role for themselves at scale. The Support Group fosters creativity, supports medical secretaries' finding of solutions and local problem solving, while at the same time working out common ground about how to use the HP and their role in the new organizational structure across the two health regions.

\subsubsection{Maintaining Digital Trajectories}

A central task of medical secretaries is to ensure that patient treatment and care is properly organized and progressing. They largely accomplish this through EHRs and by caring for the information in the patient record; for example, they ensure that bookings are made and suit all parties involved, and re-book them if not, and that doctors check and follow up on examination results.

In the following example, a group of medical secretaries are re-grounding the practices around maintaining digital trajectories as they discuss how to digitally change a patient's status. Since hospitals and other providers mostly rely on digital communication and information, it is key how secretaries interpret a patient's 'status' and digitally register it. Status can impact a patient's position in the examinations queue, depending on how urgent their case is. For this reason, medical secretaries and other professionals should reach mutual understanding and consensus about status; otherwise, some patients will wait longer than others, despite having a greater or equal need for medical care.

[Name 1]: Are you supposed to change the 'status' [urgency] if the patient is not showing up for a scheduled appointment and is terminated?

[Name 2]: Yes, because the patient is no longer waiting in that case.

[Name 3]: Can anyone tell me where I can find anything [guidelines] about the registration of a patient's status. I have looked over and over in the guidelines.

[Name 1]: I also have not solved that issue - how to change the status of a patient waiting. How-to is greatly appreciated.

[Name 2]: If I remember correctly, this can be changed in the trajectory admin. 
A Worker-Driven Common Information Space: Interventions...

(Support Group 2018)

Since the functionality and the HP were new, the medical secretaries had to work out once again the implications of different kinds of status and the 'interdependencies' within the HP between 'status' and other functionalities. In healthcare provision in which several hospitals share the responsibility for patients and have different levels of specialization, a shared practice is critical. Secretaries are interdependent when ensuring that the information infrastructure is intact. The same referral must be interpreted in the same way across hospitals and health regions to establish a coherent division of work.

Another example of re-grounding is medical secretaries' consideration of the HP's interdependencies in relation to the 'In Basket". All doctors have their individual 'In Basket', where they receive patients' test results and other notifications. The 'In Basket' is pooled as a safety precaution, where ideally more than one doctor always receives each test result. With the HP, medical secretaries must regularly remind doctors to check their 'In Basket,' as they can forget while they are busy attending to patients. If a doctor's 'In Basket' goes unchecked, it can lead to a standstill for the items awaiting response. A patient trajectory can become unnecessarily prolonged, particularly if test results end up in the wrong pool of doctors, as posts in the Support Group describe can happen, and the error is not soon discovered and corrected. As the medical secretaries attest, this requires a significant amount of time and extra work.

This articulation- and "repair work" by medical secretaries keeps the processes and systems functioning and on track; such tasks relate to the graceful and transition (retirement) from 'old' to 'new' technologies, ensuring that existing tasks, such as keeping patient trajectories on track, are still handled with care (Steinhardt 2016).

\subsubsection{Creating a New Role for Medical Secretaries Independent of Management} HP entailed a new division of work between professions with a diminished role for medical secretaries; this was clearly signalled by management when they laid off secretaries. The new divisions of work necessitated processes of articulation work for medical secretaries independent of management both to "get the work done," but also as a strategy for staying relevant as a professional group. Previously, medical secretaries transcribed doctors' dictates, making sure that new medical orders (e.g. scans and other tests) were entered into the EHR. They made sure that test results were acted upon and that patients' records were accurate and up to date. At discharge, the medical secretaries 'stitched together' and entered the necessary coding across the various databases and systems used for reimbursement, quality assessment, research, etc. With many of these tasks delegated to doctors in the HP, medical secretaries had to articulate their work and collaboration with other professions anew.

The medical secretaries aimed to meet this challenge by carving out a role as experts in the use and adaptation of the HP, bringing continuity to their role through 
the transition from the previous IT systems. Often, the medical secretaries' negotiations of a new role for themselves are subtle and folded within discussions in the Support Group CIS on how to solve concrete tasks. At other times, the negotiation of a new role is quite explicit as in the following example.

[Name1]: ...this group is for exchanging nuggets of gold I do think though it is disappointing when people write 'send a personal message ... hope this makes sense, since we are all interested in seeing the solutions to various problem in daily work. So why not provide the solution in the thread [in the FB group] rather than privately in PM [Personal Message]?

[Name 2]: $\quad$ Agree completely

[Name 3]: I see this as a forum where one can get help from likeminded colleagues. ... It is nice to get guidelines, but they take time to do, so better to have direct help via PM, than people not having the energy to help, because it is too cumbersome to write guidelines. I think there is room for both. (-)

[Name 1]: Maybe you're right ... but I'm a member of this group because I hope to learn, help others and in order for us as medical secretaries to become stronger as a group and keep up our professional pride $\boldsymbol{\epsilon}_{\boldsymbol{\sigma}}$ So if one opts for 'PM' it is ok, but with the present HP, we all muddle through, so why not share in the group those experiences that we have gained!!!

(Support Group 2017)

Not only does the Support Group work out how to accomplish specific tasks within the HP, the secretaries also quite explicitly debated the forum's role as a place for working out common ground independent of management - and retaining their professional pride. The medical secretaries also responded to management decisions in their debates in their private Support Group. Only members of the Facebook Support Group can share and comment on content posts. As illustrated by the example above, norms such as keeping the posts constructive, are collectively maintained. No one from management was or is to our knowledge members of the group and have not posted there.

The important independence of management is illustrated in several examples. In another instance a secretary asks the Support Group if there are any tasks that they can take over from the doctors, as productivity levels start to become an issue with the transition to HP. "The health region has asked us to make sure that we take over tasks 
A Worker-Driven Common Information Space: Interventions...

that can relieve doctors. Because there is a shortage of doctors in our region" (Support Group Post 2017). One member's response to this post was for the secretaries to take over the doctors' medical orders - since the secretaries were already responsible for the scheduling of examinations (blood tests etc.). Another secretary reminded her colleagues that the 'gentlemen higher up in the system' must be made aware that it is actually the medical secretaries and not the doctors who are carrying out this work, since this could save even more medical secretaries from being laid off. A third secretary pointed out that the medical secretaries would need the proper access rights and should use their own login id's to make these tasks traceable and their work visible within the HP. Other medical secretaries posted comments about how they had been preparing a catalogue of new tasks for medical secretaries.

The role of the Support Group to re-negotiate their relevance within the hospital organization and work out a new role for the medical secretaries was explicitly debated as in another comment chain, where the conversation was started by a frustrated medical secretary:

[Name 1]: I'm leaving this group- I get angry and annoyed every time I see yet another question about how to do this or that. We are the occupation that according to politicians in the region are not needed. Yet, day after day we answer questions and challenges - and use FB for this purpose - and who will thank us - NO ONE. I hoped the protest in [city] would have showed that we did not have spines like worms but...

[Name 2]: You're right, [Name1] - it can't be right that one has to use Facebook to be able to do one's work.

[Name 3]: Think it is super great that we can learn from each other - super group. Would not be without it. This is a support group- not a political group....

[Name 4]: To me this is a support group with the purpose of helping each other, so that we can endure being in a chaotic work situation. I engage in the trade union struggle in other places.. and, believe me, I do engage.

[Name5]: If one gives up on the struggle to learn and understand HP, then one also gives up on the survival of medical secretaries. Then one has given up the struggle

[Name 4]: $\quad$ Agree ... I try to go into detail with HP and turn myself into a specialist, find tasks where I can help doctors and care staff as 
well as make sure to be the patient's 'advocate' within the system. In this way, I think our occupation can survive.

[Name 5]: Exactly. The better experts we are, the less can we be ignored and the better we can opt in on new, great, and exciting tasks. To sit with our hands idle and signal to them [doctors and nurses] that they have to learn it themselves, is only to our disadvantage. We have to be innovative and become the experts again. For god's sake, we cannot become inactive or passive. We are the red thread in a white world with or without HP.

[Name 7]: Get you [Name 1]. With the implementation of HP, all occupations ought to be better off. ... It is crazy that everyone is thrown into this pool of problem, and that a third of the [medical] secretaries are to be laid off, because the system has cost a huge amount of money. Someone didn't do their homework. Who is to code, who is to call in patients for outpatient surgeries, who will tidy up all the [error] lists, who will answer the phone when patients call, who will solve the problems of the doctors [with HP], who will send copies [of patient notes] to various authorities, who will book new appointments for patients. The doctors????

(Support Group 2017)

Several things are addressed in this conversation that extends over $20+$ more comments. First, the Support Group is seen by the medical secretaries as a forum in which to solve specific problems with the new system, the HP. Second, the group's status as 'non-political' is confirmed in the sense that the group is for helping each other, and not to vent trade union issues, which are supposed to be raised elsewhere, according to the administrator of the Support Group. This 'non-political' framing is probably, we suggest, one of the reasons why the Support Group was not criticized or challenged by management or politicians, who had an interest in the HP's success and productivity levels. Content uploaded to the Support Group is not 'anything goes;' rather, it is curated by the administrator. Whenever members post messages criticizing the HP, she deletes the posts and reminds members in a friendly tone that the group is mainly for support and help with the HP. On the other hand, conversations on how to ensure a role for the medical secretaries in the future are not deleted.

Third, while avoiding critisizing HP and management, the medical secretaries work out explicit strategies through which to maintain their relevance within the organization. By becoming experts of the new system, they can continue their previous function as IT-systems experts. Taking over tasks from overburdened 
A Worker-Driven Common Information Space: Interventions...

doctors and nurses continues their function as support staff, and continuing to have contact with patients, they maintain their role as coordinates of patients' bookings, examinations, and follow-up visits. They continue to be the patients' advocates. Being 'experts' medical secretaries hoped to ensure the survival of the occupation of medical secretaries, as one member of the Support Group, [Name5], argues above.

\section{Discussion}

The concept of CIS was proposed by Bannon and Bødker amongst others (1997) at a time when the internet was just taking off and social media like Facebook had not yet been launched. Today, social media research has become an established part of CSCW, though not to the satisfaction of all. Schmidt (2009), for example, argues that much of this research has little to contribute to $\mathrm{CSCW}$, since it operates on a research paradigm of 'divorced-communication,' where technologies are seen as merely the media through which communication flows. This framework allows little or no connection to the coordinative practices of which they are part, nor does it have any implications for how to design and redesign technology.

In the present case, however, social media was used to clarify, re-ground, and coordinate tasks within the portfolio of medical secretaries' work, which is indeed cooperative (Bossen et al. 2012; Møller and Vikkelsø 2012). Furthermore, the secretaries established the Support Group/CIS to supplement the official organization for the implementation of the HP, and to facilitate the transition. The medical secretaries needed a new forum through which quickly and on a daily basis to share information to be able to do their own work and support other professionals, similar to the case reported by (Handel and Poltrock 2011) where employees set up unofficial parallel systems to handle large projects. However, there was no immediate and ongoing interaction in their case, which is one of the most important qualities of the Support Group.

Taking into consideration the recent launch of Workplace by Facebook (WbF) as a collaboration platform (Michalsen 2017), our case may be interpreted as part of a more general trend of the use of enterprise social media. Social media has already been suggested as a way to improve employee and worker co-creation in collaboration with management within healthcare (Garmann-Johnsen et al. 2018), though other authors point to the potential conflict this may entail (Schaefer 2018).

In our case, the CIS set up on Facebook differs from WbF, the licensed product, since it operated independent of the official organization and management. However, the case contributes to new questions for CSCW-research on the hybrid place-less / place-based workplace (e.g. Fitzpatrick et al. 1996; Rossitto and Lampinen 2018), and the options available for work and worker support, as new emergent 
technologies lead not only to new forms of digital work and labour, but also transform the more classic types of work.

\subsection{The Support Group and Enterprise Social Media}

The same challenges once addressed by prior research on CIS are also fundamental for emerging enterprise social media, in which organizations use 'hosted' platforms such as $\mathrm{WbF}$, Slack, etc. for internal communication and information sharing (Leonardi et al. 2013). Such platforms extend social learning across the organization by providing people visibility into the communicative actions of others and making information available and accessible over time, though this also increases the risk of information overload within the organization (Leonardi et al. 2013).

Indeed, enterprise social media seem to signal a new wave of optimism regarding IT-facilitated knowledge- and expertise sharing (Ackerman 1994; Ackerman et al. 2013). It seems especially suited for promoting employee or worker driven cocreation processes in cooperation with management in social welfare states like Denmark, Garmann-Johnsen et al. argue (2018). However, there are also fundamental challenges: What do you do as an employee when your CEO posts a new idea as his or her own on $\mathrm{WbF}$, and you realise that it is a replication of the talk you gave last week to him or her (Schaefer 2018), or your news feed is curated in problematic ways (Leonardi et al. 2013)?

The medical secretaries set up their Support Group in parallel to and outside of the official implementation organization, despite expectations that they would be obsolete to some degree with the new HP. They took on a role as drivers of the implementation, working out solutions for data errors, providing new procedures and guidelines, and taking over tasks again from overburdened doctors.

The Support Group exhibits many of the qualities that Leonardi et al. (2013) argues are characteristic for enterprise social media. The Support Group functions as a 'leaky pipe' for broad knowledge and expertise sharing, an 'echo chamber' for rebuilding common ground and a sense of belonging; and as a 'social lubricant' that helps practitioners maintain existing and initiate new connections (Leonardi et al. 2013).

Enterprise social media integrate management tools, which we argue may make a critical difference in periods of transition and change. When communities of practice such as medical secretaries are considered redundant, this exacerbates existing power dynamics between management and employees and tends to create distrust in periods of transition and change. Following Ackerman, it is critical for the success of management technologies that people trust and will use these tools (Ackerman 1994; Ackerman et al. 2013). Thus, who controls how information is managed and the transparency of that information, as well as the question of who is a member of the user group, is crucial for enterprise social media to work adequately as a CIS.

Had management and the HP implementation organization recognized the need for re-grounding practices they could have hosted something like the Support Group 
A Worker-Driven Common Information Space: Interventions...

through enterprise social media, and enabled working out new procedures, etc. However, this would have presupposed that management had recognised importance of medical secretaries in daily work and in a period of technological change. Moreover, the question is whether management would have hosted such a forum to discuss and formulate strategies for redefining and strengthening a new role for medical secretaries working with and through the HP.

\subsection{Turning Social Media into a CIS for Transition and Change}

The Support Group (CIS) in our case has similarities with third party platforms like Turkopticon and Dynamo, in the sense that it supports the medical secretaries in negotiating a stronger position for themselves vis-à-vis the new EHR, the HP. Like Dynamo, the administrator in our case also plays a critical curating role to balance friction, but she is not actively seeking to increase dialogue in case of stalling (Salehi et al. 2015).

Of course, the HP is not a digital labour platform like Mechanical Turk (Silberman and Irani 2016), and medical secretaries are not (yet) temporary employees or workers like transcriptionists or scribes in the USA (Vinik 2018). Also, they are not (yet), in the new speak of digital platforms for casual workers 'autonomous entrepreneurs.' However, it overlaps with the other instances by providing a digitally mediated forum through which to discuss work and improve workers' position. While seemingly paradoxical to some of the members of the Support Group the worker-driven CIS allows the medical secretaries to solve practical issues with the $\mathrm{HP}$ and the new division of labour long before the official support would be able to handle a formal request. This simultaneously positions the medical secretaries as HP 'experts' and continues their role as IT 'super users' and their role as central 'articulation workers' (Abraham and Reddy 2013; Bossen et al. 2014; Møller and Vikkelsø 2012). This resonates with Da Cunha and Orlikowski (2008) and Ménendez-Blanco et al. (2017), who argue that online forums can facilitate members' expression of emotional stress and at the same time enable organizational change by working through frustrations in a constructive manner.

In our case, the medical secretaries understand the deeper and intricate relationships between healthcare practice and technology that are critical for the graceful retirement of the old system (Cohn 2016; Steinhardt 2016). Most organizations, especially within healthcare, do not experience clear breaks between 'new' and 'old,' but find themselves in situations of constant technological change. Hence, while entrepreneurial innovators can be important, so are those occupations or people who 'assemble the parts while the plane is flying' or rather, as in this case, maintain data quality and keep digital trajectories on track in situations of significant change.

In this way, the case of the medical secretary Support Group is in line with prior research that points to the need for professionals invested in 'breaking down while building up' as a resource for innovation and development (Steinhardt 2016). Indeed, the members of the Support Group will argue that they have a mandate from the 
health regions to be 'change brokers,' since they were asked to consider how they could take over tasks to relieve doctors. This role was carefully maintained by the Support Group administrator, who positioned the group as a 'professional' forum for medical secretaries, and not as a place where frustrations with the new HP or the demise of the occupation of medical secretaries should be vented.

The Support Group succeeded as a CIS in a situation where its members were thought to be partly redundant, because it worked outside of the official organization. Since the Support Group significantly contributed to ensuring the implementation process moved forward, the question arises when and in which situations enterprise social media may support transition and change, since such processes will most often entail redistribution of work in a context of different interests.

\subsection{The Transformation of Work by Data-Driven Technology (Epilogue)}

Organizations risk losing knowledge and expertise if the effort of transitioning to new technology is not taken seriously, according to Volkoff et al. (2007). Around 300 medical secretaries were made redundant in 2017-2018 with the transition to the new HP. In late 2018, hospital managements realized the critical role of medical secretaries; 55 medical secretaries were rehired as the exclusion of medical secretaries turned out to be a choice that negatively affected the productivity of the hospitals. Doctors saw fewer patients, since they had to do more administrative work, and reimbursement decreased, since doctors were not as skilled with coding as medical secretaries and did not enter correct or optimal codes.

The transformation of work by new data-driven technologies is evident in the healthcare domain both in the USA and in Denmark (Møller 2018). In the USA, we observe the increasing use of 'contingent workforce', such that the USA labour market is now facing a transformation towards more independent contractors (Vinik 2018; Frey and Osborne 2017).

In Denmark, the medical secretaries were formally excluded from the implementation process of the HP, because their work was assumed to disappear or to have significantly diminished. This might also be connected to the fact that the HP was developed in the USA, where the occupation of medical secretary, which exist in Denmark and other European countries, as such does not exist. In the USA, the tasks medical secretaries take care of are divided into specialised occupations such as scribes, transcriptionists, clinical documentation improvement specialists, and coders - as well as lay secretaries.

Data-driven technologies have implications for work practices and organizations, and importing technologies from one country to another may also attend significant implications, as evident in the varied responses in different countries to digital platforms such as Uber, Lyft, and AirBnB. The work of Irani and Silberman (2013), Martin et al. (2016), and others is an encouraging continuation of the initiatives in the 1980s of how unions and researchers could develop a 
A Worker-Driven Common Information Space: Interventions...

model for negotiating with management about the introduction of new technologies in the workplace (Kraft and Bansler 1994 citing Ehn and Kyng 1987; Ehn 1988).

\section{Conclusion}

The concept of CIS has long been considered a strategy for an official organization to optimize the efficient sharing of knowledge and expertise. Organizations have often set up in-house web-based platforms that allow practitioners across an organization to efficiently support knowledge and expertise sharing.

More recently, there has been a shift towards 'hosted' platforms, utilizing the affordances of social media such as posting (Leonardi et al. 2013). However, the use of digital platforms for work purposes is not restricted to the official implementation organization. The case of the Support Group provides a case of how CIS can be leveraged for balancing considerations of the worker and organization. Workers reasonable expectations to be inyolved in the design and setup of new digital technologies with impact on their work can benefit from the support lend by a worker-driven CIS. Workers can take on a unique role in this context, we argue, through setting up a CIS independent of the formal boundaries of organizations.

CIS have been studied before in hospital contexts, but not to the best of our knowledge in a context of dramatic transformation of the overall division of work. As such, this case shows how CIS not only exist and play a constructive role in stable situations, but also have important qualities for enabling and facilitating cooperative work during periods of transition and change. This case shows how occupations may engage with new technology and stay relevant by taking an active role in the transition period. The Support Group makes visible the ripple effects of new technology and in this sense enables new types of worker engagement, as well as pointing to the importance of occupations engaged in 'building up while breaking down'.

Most important, the paper points to the qualities of a worker-driven CIS set up as an a forum for 1) the articulation work required for re-grounding changing tasks and responsibilities, 2) archiving discussions (posts) and guidelines to further their collective interpretation, and 3) providing a space independent of management for professions to work out their new role in an organization in situations of transition and change.

Questions for future research relate to the role of this kind of worker-driven CIS and labour platforms and to what extent they can take a more permanent form. What happens to the place-based workplace when it morphs into a placeless structure? What are the legitimate options of workers, bringing this kind of knowledge and expertise independent of the workplace as a strategy for staying relevant through negotiating a new role for themselves? Can the CIS independent of the official organization be a collective tool for constructive dialogue amongst 
management and workers through periods of technological change and transition? What will be the role of CIS and enterprise social media as tasks are divided differently and conventional forms of work are transformed by digitization?

\section{Acknowledgments}

We would like to direct a particular thank you to the medical secretaries of the Support Group who allowed us to follow their daily interactions - as well as the practitioners who participated in interviews. We would also like to thank colleagues Geraldine Fitzpatrick, Jørgen P. Bansler, Kjeld Schmidt, and others in the CompArt research project who discussed with us the early draft of this paper as well as Pernille Bjørn, Jakob Grue Simonsen, and Aske Mottelson. This research was supported by the Velux Foundations award number 33295 and conducted as part of the Computational Artefact (CompArt) research project.

\section{References}

Abdulgalimov, Dinislam; Reuben Kirkham; James Nicholson; Vasilis Vlachokyriakos; Pam Briggs; and Patrick Olivier. (2020). Designing for employee voice. CHI 2020. Proceedings of the 2020 CHI Conference on Human Factors in Computing Systems. New York: ACM Press, pp. 1-13.

Abraham, Joanna; and Madhu C. Reddy (2013). Re-coordinating activities: an investigation of articulation work in patient transfers. CSCW 2013. Proceedings of the ACM Conference on Computer Supported Cooperative Work and Social Computing, New York: ACM Press, pp. 67-78.

Ackerman, Mark S. (1994). Augmenting the organizational memory: A field study of answer garden. CSCW 1994. Proceedings of the ACM Conference on Computer Supported Cooperative Work and Social Computing, New York: ACM Press, pp. 243-252.

Ackerman, Mark S.; Juri Dachtera; Volkmar Pipek; and Volker Wulf (2013). Sharing knowledge and expertise: The CSCW view of knowledge management. Computer Supported Cooperative Work (CSCW), vol. 22, no. 4-6, pp. 531-573.

Ajami, Sima; and Tayyebe Bagheri-Tadi (2013). Barriers for adopting electronic health records by physicians. Acta Informatica Medica, vol. 21, no. 2, Article 129.

Andersen, Tariq O.; Jørgen P. Bansler; Finn Kensing; Jonas Moll; Troels Mønsted; Karen D. Nielsen; $\ldots$ and Jesper H. Svendsen (2018). Aligning concerns in telecare: Three concepts to guide the design of patient-centred e-health. Computer Supported Cooperative Work (CSCW), vol. 27, no. 36, pp. 1181-1214.

Bannon, Liam (2000). Understanding common information spaces in CSCW. Position paper for Workshop on Common Information Spaces, Copenhagen, Denmark, August 23-25 2000. http:// cscw.dk/ciscph2000/Bannon.pdf. Accessed November 52012.

Bannon, Liam; and Susanne Bødker (1997). Constructing common information spaces. In J. A. Hughes, et al. (eds): ECSCW'97: Proceedings of the Fifth European Conference on ComputerSupported Cooperative Work, 7-11 September 1997, Lancaster, U.K. Dordrecht: Kluwer Academic Publisher, pp. 81-96.

Bertelsen, Olav W; and Susanne Bødker (2001). Cooperation in massively distributed information spaces. In W. Prinz, et al. (eds): ECSCW 2001: Proceedings of the Seventh European Conference on Computer Supported Cooperative Work, 16-20 September 2001, Bonn, Germany. Dordrecht: Kluwer Academic Publishers, pp. 1-17. 


\section{A Worker-Driven Common Information Space: Interventions...}

Bertelsen, Pernille; and Christian Nøhr (2005). The work practice of medical secretaries and the implementation of electronic health records in Denmark. Health Information Management, vol. 34, no. 4, pp. 104-111.

Blomberg, Jeannette; Lucy Suchman; and Randall Trigg (1997). Reflections on a work-oriented design project. In Geoffrey Bowker, Susan Leigh Star, William Turner, and Les Gasser (eds.): Social Science, Technical Systems and Cooperative Work: Beyond the Great Divide. Hillsdale, NJ: Erlbaum, pp. 189-215.

Bossen, Claus (2002). The parameters of common information spaces - the heterogeneity of cooperative work of a hospital ward. CSCW 2002. Proceedings of the ACM Conference on Computer Supported Cooperative Work and Social Computing, New York: ACM Press, pp. 1620.

Bossen, Claus. (2011). Accounting and co-constructing: The development of a standard for electronic health records. Computer Supported Cooperative Work (CSCW), vol. 20, no. 6, pp. 473-495.

Bossen, Claus; Lotte Groth Jensen; and Flemming Witt (2012). Medical secretaries' care of records: the cooperative work of a non-clinical group. CSCW 2012. Proceedings of the ACM Conference on Computer Supported Cooperative Work and Social Computing, New York: ACM Press, pp. 821830.

Bossen, Claus; Lotte Groth Jensen; and Flemming Witt (2014). Boundary-object trimming: On the invisibility of medical secretaries' care of records in healthcare infrastructures. Computer Supported Cooperative Work (CSCW), vol. 23, no. 1, pp. 75-110.

Bossen, Claus, Naja Holten Møller; Pernille Bertelsen; and Signe Vikkelsø (2017). 'Lægesekretærers rolle i digitaliseringen overses.' [Medical secretaries' role in digitalization is disregarded], In Dagens Medicin, no. 6, 17 March 2017.

Bossen, Claus; Yunan Chen; and Kathleen H. Pine (2019a). The emergence of new data work occupations in healthcare: The case of medical scribes. International Journal of Medical Informatics, vol. 123, pp. 76-83.

Bossen, Claus, Kathleen H. Pine; Federico Cabitza; Gunnar Ellingsen; and Enrico M. Piras (2019b). Data work in healthcare: An introduction. Special issue. Health Informatics Journal, vol. 25, no. 3, pp. 465-474.

Boulus-Rødje, Nina. (2018). In search for the perfect pathway: Supporting knowledge work of welfare workers. Computer Supported Cooperative Work (CSCW), vol. 27, no. 3-6, pp. 841-874.

Bødker, Susanne (1993). Historical analysis and conflicting perspectives-contextualizing HCI. CHI 1993. Proceedings of the ACM International Conference on Human-Computer Interaction, New York: ACM Press, pp. 1-10.

Bødker, Susanne (1994). Creating conditions for participation: Conflicts and resources in systems design. Aarhus, Denmark: University of Aarhus. DAIMI Report Series, vol. 13, no. 479.

Cohn, Marisa (2016). Convivial decay: Entangled lifetimes in a geriatric infrastructure. CSCW 2016. Proceedings of the ACM Conference on Computer Supported Cooperative Work and Social Computing, New York: ACM Press, pp. 1511-1523.

Clark, Herbert H; and Susan E. Brennan (1991). Grounding in communication. Perspectives on Socially Shared Cognition, vol. 13, pp. 127-149.

Da Cunha, João Vieira; and Wanda J. Orlikowski (2008). Performing catharsis: The use of online discussion forums in organizational change. Information and Organization, vol. 18, no. 2, pp. 132-156.

Denyer, David, Emma Parry; and Paul Flowers (2011). "Social", "Open" and "Participative"? Exploring personal experiences and organisational effects of enterprise 2. 0 use. Long Range Planning, vol. 44, no. 5-6, pp. 375-396.

Dombrowski, Lynn; Adriana Alvarado Garcia; and Jessica Despard (2017). Low-wage precarious workers' sociotechnical practices working towards addressing wage theft. CHI 2017. Proceedings of the ACM Conference on Human Factors in Computing Systems, New York: ACM Press, pp. 4585-4598. 
Ehn, Pelle (1988). Work-Oriented Design of Computer Artifacts. Stockholm: Arbetslivscentrum.

Ehn, Pelle; and Morten Kyng (1987). The collective resource approach to systems design. In G. Bjerknes; P. Ehn; and M. Kyng (eds): Computers and Democracy: A Scandinavian Challenge. Aldershot, England: Avebury, pp. 17-57

England, Kim; and Kate Boyer (2009). Women's work: The feminization and shifting meanings of clerical work. Journal of Social History, vol. 43, no. 2, pp. 307-340.

Frey, Carl B; and Michael A. Osborne (2017). The future of employment: how susceptible are jobs to computerisation? Technological forecasting and social change, vol. 114, pp. 254-280.

Fiore-Gartland, Brittany; and Gina Neff (2015). Communication, mediation, and the expectations of data: Data valences across health and wellness communities. International Journal of Communication, vol. 9, pp. 1466-1484.

Fitzpatrick, Geraldine; and Gunnar Ellingsen (2012). A review of 25 years of CSCW research in healthcare: Contributions, challenges and future agendas. Computer Supported Cooperative Work (CSCW), vol. 22, pp. 609-665.

Fitzpatrick, Geraldine; Simon Kaplan; and Tim Mansfield (1996). Physical spaces, virtual places and social worlds: A study of work in the virtual. In G. M. Olson; J. S. Olson; and M. S. Ackerman (eds): CSCW'96: Proceedings of the Conference on Computer-Supported Cooperative Work, 1620 November 1996, Boston, Mass. New York: ACM Press, pp. 334-343.

Garmann-Johnsen, Niels F; Migle Helmersen; and Tom R. Eikebrokk (2018). Digital transformation in healthcare: Enabling employee co-creation through web 2.0. Americas Conference on Information Systems, Health, Article 21.

Glaser, Barney G.; and Anselm L. Strauss (1967). The Discovery of Grounded Theory: Strategies for Qualitative Research, Chicago: Aldine Publishing Company.

Greenhalgh, Trisha; Henry W. Potts; Geoff Wong; Pippa Bark; and Deborah Swinglehurst (2009). Tensions and paradoxes in electronic patient record research: A systematic literature review using the meta-narrative method. Milbank Quarterly, vol. 87, no. 4, pp. 729-788.

Handel, Mark J; and Steven Poltrock (2011). Working around official applications: experiences from a large engineering project. In P. J. Hinds, et al. (eds): CSCW 2011: Proceedings of the ACM 2011 Conference on Computer Supported Cooperative Work, Hangzhou, China, 19-23 March 2011. New York: ACM Press, pp. 309-312.

Harmon, Ellie; and Six M. Silberman (2018). Rating working conditions on digital labor platforms, in T. Ludwig et al. (eds) Special Issue on Crowd Dynamics: Conflicts, Contradictions, and Cooperation Issues in Crowdsourcing, Computer Supported Cooperative Work (CSCW), vol. 27, no. 3-6, pp. 1275-1324.

Heinrich, Peter; Alexander Richter; Lars Rune Christensen; and Gerhard Schwabe (2018). Creating, reinterpreting, combining, cuing: Paper practices on the shopfloor. GROUP 2018. Proceedings of the 2018 ACM Conference on Supporting Groupwork, New York: ACM Press, pp. 274-283.

Hertzum, Morten and Gunnar Ellingsen (2019). The implementation of an electronic health record: Comparing preparations for Epic in Norway with experiences from the UK and Denmark. International Journal of Medical Informatics, vol. 129, pp. 312-317.

Hine, Christine (2000) Virtual Ethnography. London, SAGE.

Hoeyer, K. (2016). Denmark at a crossroad? Intensified data sourcing in a research radical country, The Ethics of Biomedical Big Data. B. D. Mittelstadt and L. Floridi. Cham, Springer, pp. 73-93.

Hogle, Linda F. (2016). Data-intensive resourcing in healthcare. BioSocieties, vol. 11, no. 3, pp. 372-393.

Hsu, Wendy (2012). On digital ethnography, what do computers have to do with ethnography? https:// ethnographymatters.net/blog/2012/10/27/on-digital-ethnography-part-one-what-do-computershave-to-do-with-ethnography/

Irani, Lilly; and Six M. Silberman (2013). Turkopticon: Interrupting worker invisibility in Amazon Mechanical Turk. CHI 2013. Proceedings of the ACM Conference on Human Factors in Computing Systems, New York: ACM Press, pp. 611-620. 


\section{A Worker-Driven Common Information Space: Interventions...}

Irani, Lilly (2015). The cultural work of microwork. New Media and Society, vol. 17, no. 5, pp. 720 739.

Kim, Jiyqung; Anja Bechmann; and Han Woo Park (2017). Digital divide and network externality in personal network size and online group membership on Facebook. Digital Media Sociology in a Digital Cross-Platform World, NordMedia, University of Tampere, 2017, August 1719.

Kraft, Philip; and Jørgen P. Bansler (1994). The collective ressource approach: the Scandinavian experience. Scandinavian Journal of Information Systems, vol. 6, no. 1, pp. 71-84.

Kristiansen, Kristian Helbo; Mathias A. Valeur-Meller; Lynn Dombrowski; and Naja Holten Møller (2018). Accountability in the data-driven blue-collar workplace. CHI 2018. Proceedings of the ACM Conference on Human Factors in Computing Systems, New York: ACM Press, Article 332.

Leonardi, Paul M; Marleen Huysman; and Charles Stenfield (2013). Enterprise social media: Definition, history and prospects for the study of social technologies in organizations. Journal of Computer-Mediated Communication, vol. 19, no. 1, pp. 1-19.

Lave, Jean; and Etienne Wenger (1991). Situated learning: Legitimate Peripheral Participation. Cambridge, Cambridge University Press.

Markussen, Randi (1996). Politics of intervention in design: Feminist reflections on the Scandinavian tradition, AI \& Society, vol. 10, pp. 127-141.

Martin, Dave; Jackie O’Neill; Neha Gupta; and Benjamin V. Hanrahan (2016). Turking in a global labour market. Computer Supported Cooperative Work (CSCW), vol. 25, no. 1, pp. 39-77.

Ménendez-Blanco, Maria; Antonella De Angeli; and Maurizio Teli (2017). Biography of a design project through the lens of a Facebook page. Computer Supported Cooperative Work (CSCW), vol. 26, pp. 71-96.

Michalsen, Gard L. (2017). Facebook at Work har allerede kapret Norges største selskaper. I dag bytter tjenesten navn og blir tilgjengelig for alle. Medier24. Accessed 29.06.18 from https:// www.medier24.no/artikler/facebook-at-work-har-allerede-kapret-norges-storste-selskaper-i-dagbytter-tjenesten-navn-og-blir-tilgjengelig-for-alle/365001

Michael-Muller (2012). Lurking as personal trait or situational disposition: lurking and contributing in enterprise social media. CSCW 2012. Proceedings of the ACM Conference on Computer Supported Cooperative Work and Social Computing, ACM, pp. 253-256.

Mølsted, Henning; and Rebecca Falsing (2017a). Sundhedsplatformen opgaverne har bare skiftet hænder. Version 2. Accessed 10.05.2018 from https://www.version2.dk/artikel/ sundhedsplatformen-opgaverne-har-bare-skiftet-haender-1081114

Mølsted, Henning; and Rebecca Falsing (2017b). Lægesekretærer om journaler efter sundhedsplatformen. Det ser ud ad helvede til. Accessed 17.10.2018 https://www.version2.dk/ artikel/sundhedsplatformen-opgaverne-har-bare-skiftet-haender-1081114

Møller, Naja Holten; Geraldine Fitzpatrick; and Christopher Le Dantec (2019). Assembling the case: Citizens' strategies for exercising authority and personal autonomy in social welfare. GROUP 2019. Proceedings of the ACM Conference on Supporting Group Work, New York: ACM Press, Article 244.

Møller, Naja Holten (2018). The future of clerical work is precarious. ACM Interactions. Vol. 25, no. 4, pp. 75-77.

Møller, Naja Holten; Pernille Bjørn; Jonas Christopher Villumsen; Tine C. Hansen Hancock; Toshimitsu Aritake; and Shigeyuki Tani (2017a). Data tracking in search of workflows. CSCW 2017. Proceedings of the ACM Conference on Computer Supported Cooperative Work and Social Computing, Portland Oregon, February, 2017. New York: ACM Press, pp. 2153-2165.

Møller, Naja Holten; Irina Shklovski; Six Silberman; Lynn Dombrowski; and Airi Lampinen (2017b). A constructive-critical approach to the changing workplace and its technologies. ECSCW 2017. Proceedings of the European Conference on Computer-Supported Cooperative Work - Panels, Posters and Demos, Reports of the European Society for Socially Embedded Technologies, vol. 1, no. 3, pp. 2510-2591. https://doi.org/10.18420/ecscw2017_p2 
Møller, Naja Holten; and Klaus Bruhn Jensen (2016). Making sense of medical records in a nonmedical practice. CHI 2016. Position paper presented at the ACM Conference on Human Factors in Computing Systems https://ethicalencountershci.com/chi-2016/position-papers-chi-2016/

Møller, Naja Holten; and Signe Vikkelsø (2012). The clinical work of secretaries: exploring the intersection of administrative and clinical work in the diagnosing process. In Julie Dugdale et al. (Eds.): COOP 2012. From Research to Practice in the Design of Cooperative Systems: Results and Open Challenges. Proceedings of the 10th International Conference on the Design of Cooperative Systems, 30 May - 1 June, 2012, London: Springer, pp. 33-47.

Møller, Naja Holten; and Pernille Bjørn (2011). Layers in sorting practices: Sorting out patients with potential cancer. Computer Supported Cooperative Work (CSCW), vol. 20, no. 3, pp. 123-153.

Møller, Naja Holten; Claus Bossen; Kathleen H. Pine; Trine Rask Nielsen; and Gina Neff (2020). Who Does the Work of Data? ACM Interactions, vol. 27, no. 3, pp. 52-55.

Mørck, Peter; Tue Odd Langhoff; Mads Christopersen; Anne Kirstine Møller; and Pernille Bjørn (2018). Variations in oncology consultations: How dictation allows variations to be documented in standardized ways. Computer Supported Cooperative Work (CSCW), vol. 27, no. 3-6, pp. 539-568.

Olson, Gary M.; and Olson, Judith S. (2000). "Distance matters". Human-Computer Interaction, vol. 15 , pp. 139-178.

Pine, Katie H; Christine Wolf; and Melissa Mazmanian (2016). The work of reuse: Birth certificate data and healthcare accountability measurements, Proceedings of the iConference. - http:// hdl.handle.net/2142/89310

Pink, Sarah (2015). Digital Ethnography: Principles and Practice. London: SAGE.

Region Hovedstaden (2019). Facts about the Health Platform. Accessed 14.07.2020. https:// www.regionh.dk/til-fagfolk/Sundhed/sundhedsplatformen/omsundhedsplatformen/Sider/Fakta-omSundhedsplatformen.aspx

Rigsrevisionen (2018). Extract from Rigsrevisionen's report on Sundhedsplatformen submitted to the Public Accounts Committee. [Copenhagen]: Statsrevisorerne, Rigsrevisionen, June 2018. http:// uk.rigsrevisionen.dk/media/2104860/17-2017.pdf

Rossitto, Chiara; and Airi Lampinen (2018). Co-creating the workplace: Participatory efforts to enable individual work at the Hoffice. Computer Supported Cooperative Work (CSCW), vol. 27, no. 3-6, pp. 947-982.

Salehi, Niloufar; Lilly C. Irani, Michael S. Bernstein, Ali Alkhatib; Eva Ogbe, Kristy Milland; and Clickhappier (2015). We are Dynamo: Overcoming stalling and friction in collective action for crowd workers. CHI 2015. Proceedings of the ACM Conference on Human Factors in Computing Systems, New York: ACM Press, pp. 1-10.

Schaefer, Stefan (2018). This does not feel like work: Social media technologies in the workplace. Pufendorfinstitutets skriftserie, pp. 35-42.

Schmidt, Kjeld (2009). Divided by a common acronym: On the fragmentation of CSCW. In I. Wagner, et al. (eds.): ECSCW 2009: Proceedings of the Eleventh European Conference on Computer- Supported Cooperative Work, 7-11 September 2009. Vienna. London: Springer, 2009, pp. 223-242.

Schmidt, Kjeld; and Liam Bannon (1992). Taking CSCW seriously: supporting articulation work. Computer Supported Cooperative Work (CSCW), vol. 1, no. 1-2, pp. 7-40.

Schmidt, Kjeld; and Liam Bannon (2013). Constructing CSCW: The first quarter century. Computer Supported Cooperative Work (CSCW), vol. 22, no. 4, pp. 345-372.

Sellen, Abigail J; and Richard Harper (2002). The Myth of the Paperless Office, Cambridge, Mass.: MIT Press.

Silberman, Six M; and Lilly Irani (2016). Operating an employer reputation system: Lessons from Turkopticon, 2008-2015. Comparative Labor Law \& Policy Journal. http://ssrn.com/abstract $=2729498(20 / 03 / 2016)$ 


\section{A Worker-Driven Common Information Space: Interventions...}

Silberman, Six M; Lilly Irani; and Joel Ross (2010). Ethics and tactics of professional crowdwork. $X R D S$, vol. 17, no. 2, pp. 39-43.

Steinhardt, Stephanie B. (2016). Breaking down while building up: Design and decline in emerging Infrastructures. CHI 2016. Proceedings of the ACM Conference on Human Factors in Computing systems, New York: ACM Press, pp. 2198-2208.

Strauss, Anselm L.; Shizuko Y. Fagerhaugh; Barbara Suczek; and Carolyn L. Wiener (1985). Social Organization of Medical Work. Chicago and London: University of Chicago Press.

Suchman, Lucy (1983). Office procedures as practical action: Models of work and system design. ACM Transactions on Office Information Systems, vol. 1, no. 4, pp. 320-328.

Sun, Na; Patrick Pei-Luen Rau; and Liang Ma (2014). Understanding lurkers in online communities: A literature review. Computers in Human Behavior, vol. 38, pp. 110-117.

Truss, Catherine; Kerstin Alfes; Amanda Shantz; and Amanda Rosewarne (2012). Still in the ghetto? Experiences of secretarial work in the 21st century. Gender, Work \& Organization, vol. 20, no. 4, pp. 349-363.

Vinik, Danny (2018). The real future of work. Politico Magazine. Jan/Feb 2018; https:// www.politico.com/magazine/story/2018/01/04/future-work-independent-contractors-alternativework-arrangements-216212

Volkoff, Olga; Diane M. Strong; Michael B. Elmes (2007). Technological embeddedness and organizational change. Organization Science, vol. 18, no. 5, pp. 832-848.

Workplace by Facebook (2019). Accessed 09.02.2019 from https://www,facebook.com/workplace/ pricing?source=topbar

Zhang, Zhan; Aleksandra Sarcevic; and Claus Bossen (2017). Constructing common information spaces across distributed emergency medical teams. CSCW 2017. Proceedings of the ACM Conference on Computer Supported Cooperative Work and Social Computing, Portland Oregon, February, 2017. New York: ACM Press, pp. 934-947.

Publisher's Note Springer Nature remains neutral with regard to jurisdictional claims in published maps and institutional affiliations. 